\title{
The introduction of a USN-based Fire Protection Model: regarding the Seomun Traditional Market in Daegu, Korea
}

\author{
Junho. Choi, Gyuyeob. Jeon \& Wonhwa. Hong \\ Department of Architectural Engineering, \\ Kyungpook National University, Republic of Korea
}

\begin{abstract}
A fire always lurks close to us in relation to our lives. Many fire accidents that cause casualties and loss of property have been described in newspapers arousing people's attention to safety. A typical example is the fire that occurred at Seomun Market in Daegu, Korea in December 2005. According to a report of the Fire Department, the fire caused about 100 million dollars worth of damage. The stores and shops in traditional market places have long played a central role in the transaction of goods and services, however, these markets have been on the decline recently because the stores have been poorly designed and constructed. These markets have not responded to environmental changes either internally or externally, so there is always a potential risk of fire. In order to prevent fires at traditional markets, the Korean government decided to install the U-FPMS (Ubiquitous Computing-based Fire Protection and Management System) in the Seomun Market Place in order to detect fire. Like this, the materialization of ubiquitous computing which is capable of communication anywhere is being developed due to the advancement of Information and Network Technology. Such technology provides a better environment for civilization. We use these ubiquitous technologies to bring about a more efficient and safer way of conducting our lives. This research introduces the U-FPMS and discusses how to make use of ubiquitous computing with regard to fire protection.

Keywords: Fire Protection, ubiquitous computing, Seomun Traditional Market Place, U-FPMS, USN, RFID.
\end{abstract}




\section{Introduction}

\subsection{Background and purpose of the current study}

Human beings have the ability to create fire, and it has become indispensable to our lives. However, because fire can also be dangerous, accidents can always occur. In 2006, there were 31,778 fires in the Republic of Korea that incurred 2,180 casualties and 150 million dollars of worth of damage. In particular, due to the structural design and the materials used in the construction of traditional markets, particular attention is directed toward these places considering their potential with regard to fire. A fire broke out at the Seomun Traditional Market in Daegu in December 2005. It incurred losses of over a 100 million dollars and the market was completely destroyed. The city of Daegu has experienced several high profile fires such as the Daegu Subway Fire (2003) and Sangindong Gas Explosion Accident (1995), this forced the city to pay more attention to fire safety. As a countermeasure, the city installed the U-FPMS at the Seomun Traditional Market. Accordingly, the U-FPMS is based on ubiquitous computing.

\subsection{Scope and method of the current study}

An inquiry and theoretical analysis regarding to the market place fire and ubiquitous computing were conducted. After analyzing the U-FPMS, this research will show how to apply ubiquitous computing to Korean Traditional Market places with regard to fire prevention.

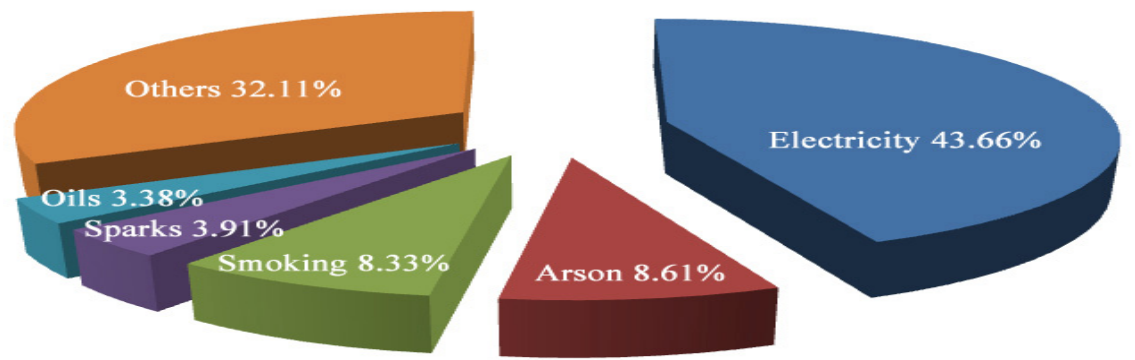

Figure 1: $\quad$ Fire Statistics classified according to Cause (NEMA, [9]).

\section{An analysis of traditional market place fires}

\subsection{Statistical analysis}

Fires in market places frighten and threaten the public because tremendous loss of property is incurred. In particular, Traditional Market places are susceptible to fires because of the increasing use of electrical machinery, gas burners and heating and cooking appliances. According to fire statistics issued by the 
National Emergency Management Agency (NEMA, Korea) in 2005, 3,794 fires broke out at commercial market places such as shops and stores; $11.8 \%$ of those fires completely destroyed the building, showing a 3\% increase over the previous year. The leading cause of fire was followed by electrical $(43.66 \%)$, arson (8.61\%), smoking-related (8.33\%), sparks (3.91\%), and oil (3.38\%).

\subsection{Causes and problems of fires within traditional market places}

In Korea, fire departments pay particular attention to traditional markets given their proclivity to fire. There are many reasons for this including the display of items in these markets and their high-volume of largely unregulated traffic. A predominant trait of these places is that once a fire breaks out, it burns violently and spreads wildly under the influence of crowded infrastructures and heavily-loaded goods. Furthermore, thick smoke and poisonous gas, which obstruct fire-fighting activity, can further exacerbate problems are generated by petrochemicals. The main causes of fire at Korean Traditional Market place include faulty wiring, cigarette butts and gas and oil, or electric heaters that are used during winters. In addition, buildings that are made of combustible timber, obsolete equipment and boilers are also fire hazards. There is no use in placing an emphasis on combating fire unless these places take measures in preventing fires in the first place.

\subsection{A case study of the Seomun Traditional Market place fire}

Seomun Traditional Market is one of the oldest markets in Korea. It has a floating population and a complex moving line. The following offers a summary of the building's specifics:

Table 1: $\quad$ The introduction of fire at Seomun Traditional Market.

\begin{tabular}{|l|l|}
\hline $\begin{array}{l}\text { Date and Duration } \\
\text { of Fire }\end{array}$ & December 29, 2005 21:57 - December 30, 2005 17:57 \\
\hline Location & The 2nd District of Seomun Market, Daegu, Korea \\
\hline $\begin{array}{l}\text { Year of } \\
\text { Construction }\end{array}$ & 1970 (Renovated Several Times) \\
\hline Building Structure & $\begin{array}{l}\text { Reinforced Concrete } \\
\text { Five floors including 1 underground floors }\end{array}$ \\
\hline Gross Floor Area & 20,188 $\mathrm{m}^{2} / 1,278$ Stores $\left(15.8 \mathrm{~m}^{2} /\right.$ store) \\
\hline Cause of Fire & Short Circuit of Electrical Wiring \\
\hline $\begin{array}{l}\text { Areas of Building } \\
\text { affected }\end{array}$ & $\begin{array}{l}\text { Underground: Restaurants, Supermarkets } \\
\text { First Floor: Bed wares, Clothing Stores } \\
\text { Second and Third Floor: Fabrics, Cottons Stores } \\
\text { Fourth Floor: Warehouse }\end{array}$ \\
\hline
\end{tabular}



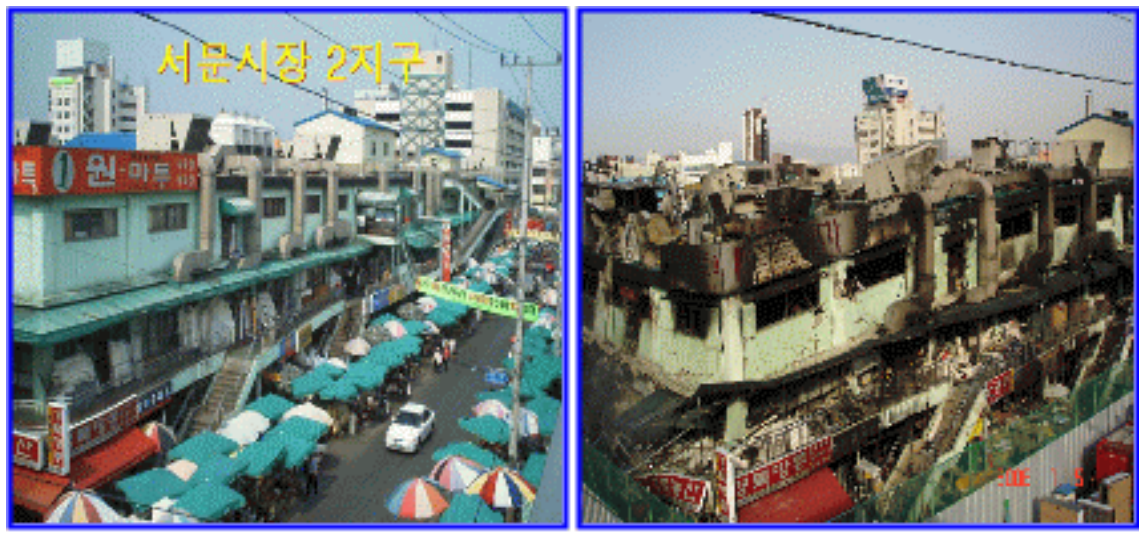

Figure 2: $\quad$ Before (L) and after (R) the fire.
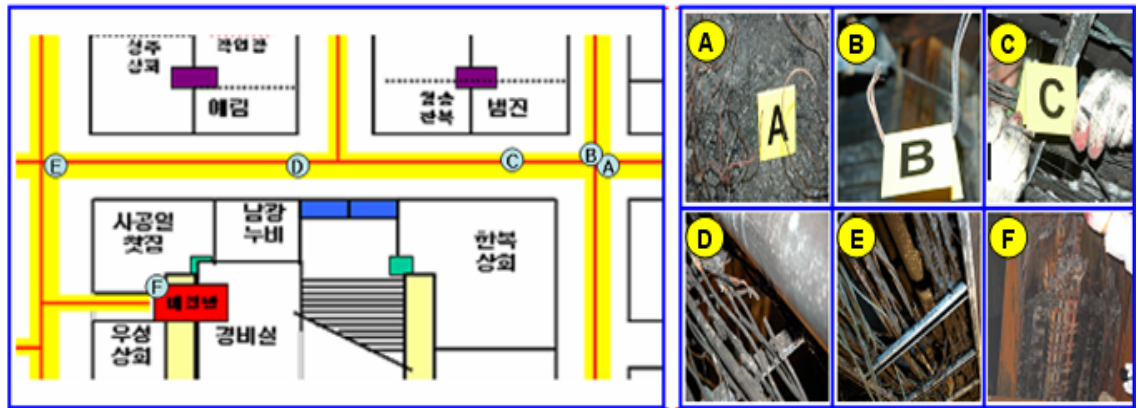

Figure 3: $\quad$ Scene of the fire and short circuit marks.

As a result of the fire, 10,500 square meters of the building (gross floor area was 19,992 square meters) were destroyed. Except for the underground space, $50 \%$ of the first floor, $80 \%$ of the second and the third floor were destroyed. It was proved that the fire was caused by an electrical short circuit. Evidence showed that an electric wire was cut and melted in the ceiling near a blanket shop and in the aisle in front of a clothing store on the first floor. We also found evidence of short circuits on the floor of point $A$, in the ceiling tray with electric wires (point B) and a few marks along the aisle (points A to F). From this, it can be concluded an electrical arc, which had a high temperature and originated from the old electrical wiring system caused a fire. The Fire Department found that the building renovations, crowded stores, and the high concentration of combustible fabrics further expanded the fire. In addition, while the fire broke out at the electric PIT on the first floor, located in the centre of the building, it moved to other floors. If these dangerous factors had been checked and monitored, such a terrible tragedy must not have broken out. 


\section{The application of ubiquitous computing to Fire Protection}

\subsection{A definition of ubiquitous computing}

Ubiquitous computing integrates computation into the environment, rather than regarding computers as distinct objects. Other terms for ubiquitous computing include 'pervasive computing', 'calm technology', 'things that think', 'everyware', and more recently, 'pervasive Internet'. Promoters of this idea hope that embedding computing into the environment and everyday objects would enable people to interact with information-processing devices more naturally and easily than they currently do. The efficient use of ubiquitous computing can be used to prevent many disasters such as floods, earthquakes, typhoons and crime. Needless to say, if ubiquitous computing is used for fire protection, this will prevent fires from occurring.

\subsection{A theoretical analysis regarding the basic technologies of ubiquitous computing}

The most typical types of technology regarding ubiquitous computing are classified into sensor, processor, communication, interface and security technology. As these types of ubiquitous technology are now useful in disaster prevention. As an example of sensor technology, Smart-dust devices are tiny wireless MicroElectroMechanical Sensors (MEMS) that can detect everything from light to vibrations. Thanks to recent breakthroughs in silicon and fabrication techniques, these motes could eventually be the size of a grain of sand, though each would contain sensors, computing circuits, bidirectional wireless communication technology and a power supply. Motes would gather scads of data, run computations and communicate information using a two-way band radio up to distances of 1,000 feet. Actually, they are being used to monitor the structure of the Golden Gate Bridge in San Francisco.

\subsection{The application of ubiquitous computing to Fire Protection}

Ubiquitous Sensor Network (USN), one type of the ubiquitous computing technology, can be applied to fire protection. This is done by allowing an electronic tag, which is attached to objects, to sense the surrounding environment. It monitors environmental data such as light, sound, temperature, movement and then the information is delivered to the information system. Existing fire equipment such as alarms, sprinklers and fire doors cannot cope with a fire until it starts. Causes of fire such as short circuits or arson can be quickly detected by a ubiquitous sensor network. Malfunctions in wiring and circuitry can be detected well in advance of their occurrence. For fire protection, a USN is easy to install because most sensors are wireless. Furthermore, it is possible to integrate various sensors or controllers, thereby providing many services. 


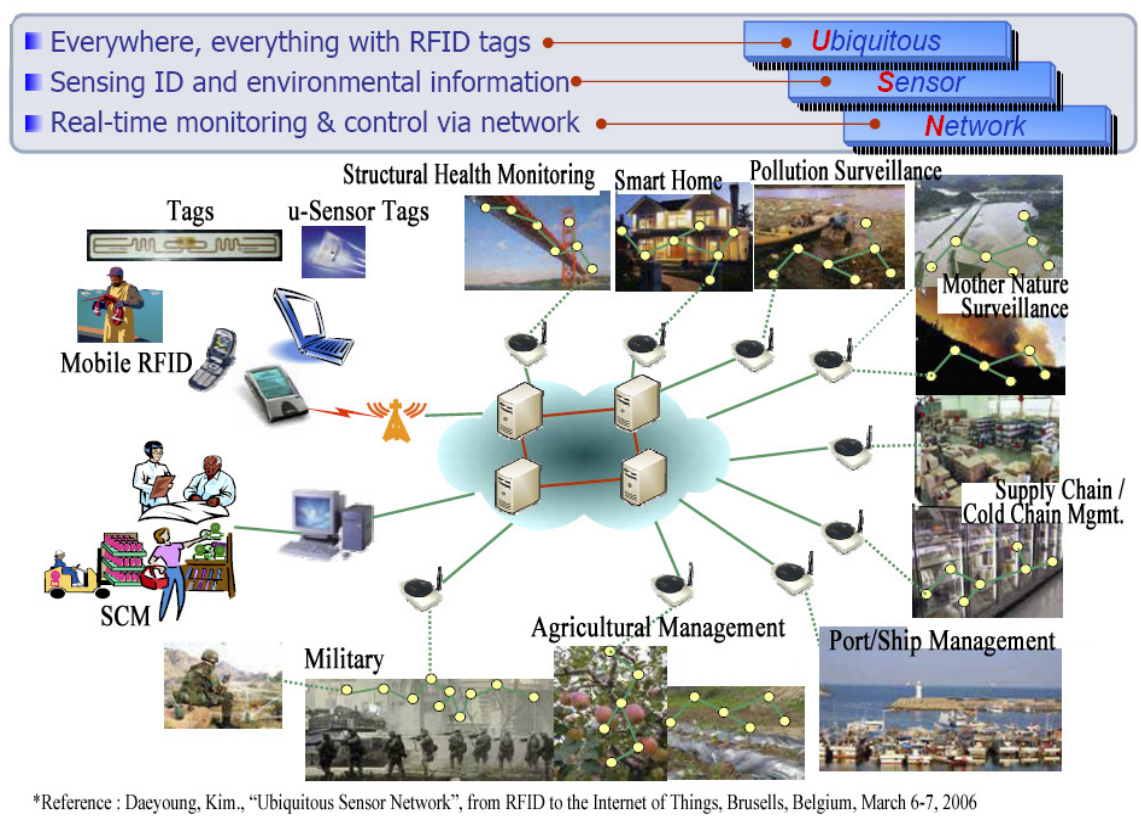

Figure 4: Ubiquitous Sensor Network (USN).

\section{U-FPMS and efficiency}

\subsection{U-FPMS Scheme}

It is very important to determine the location of a fire and to sound an alarm early in a structure such as the Seomun Traditional Market building, however, main force of the first countermeasures are dependent on the sprinkler systems combined with heat sensors. It is difficult to distinguish defect from normal conditions or to perceive a fire in the early stages. To solve this problem, an intelligent fire monitoring system and a disaster report agent system are needed, which can utilize the smart sensor and wireless network technology.

\subsection{The principles of U-FPMS}

The USN Terminal Node, which can extend over all areas, is installed throughout every ceiling of Dongsan building in Seomun market in order to detect a fire as quickly as possible. The sensor can detect smoke, temperature and sparks immediately. Although the emergency power supply is shut off, the sensor can be powered normally over a seven-day period. The USN Terminal Node is comprised of extra nodes in order to solve a shadow problem and to relay data. The USN Ethernet Gateway Node, which connects the USN to the server, can relay node or sensor data from the USN. 

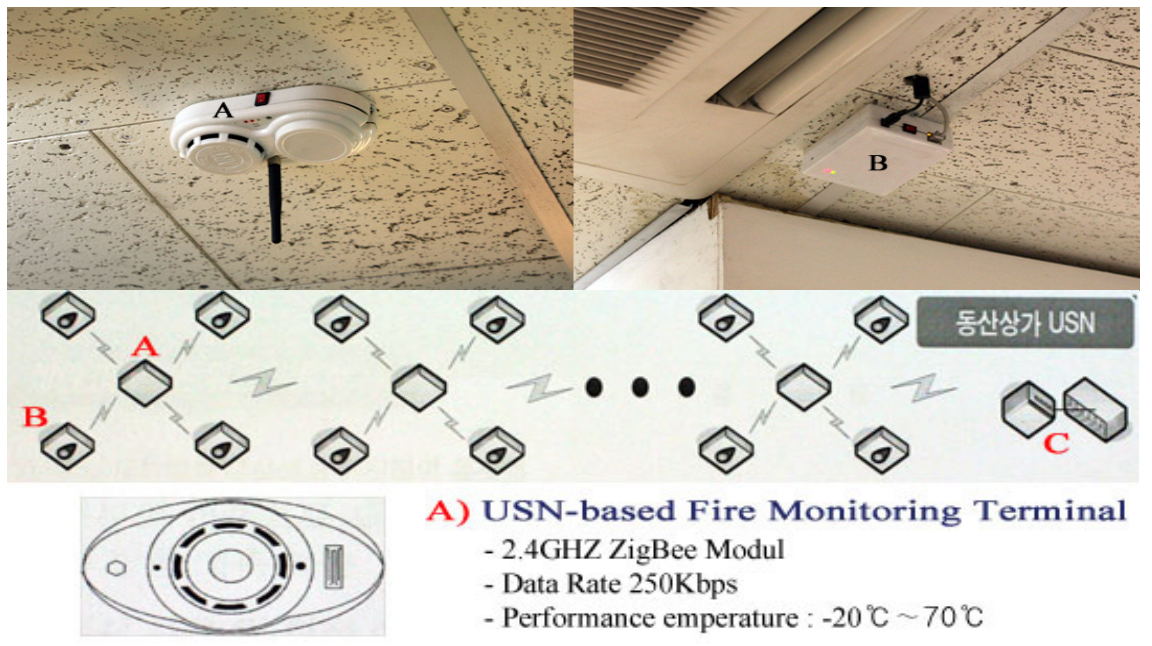

A) USN-based Fire Monitoring Terminal

- 2.4GHZ ZigBee Modul

- Data Rate 250Kbps

- Performance emperature : $-20^{\circ} \mathrm{C} \sim 70^{\circ} \mathrm{C}$

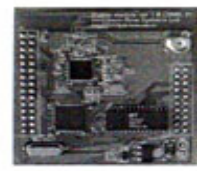

B) Sensor-integrated USN Terminal

- Spark Sensor

- Smoke Sensor

- Temperature Sensor

- USN Node

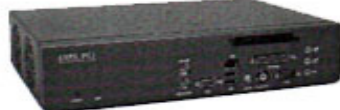

C) USN-Ethernet Gateway Terminal

- Intel IXP425 MPU - WAN 1 port

- LAN 2 port - UART 4 port

Fire Protection \& Management System based on Ubiquitous Sensor Network at Seomun Market
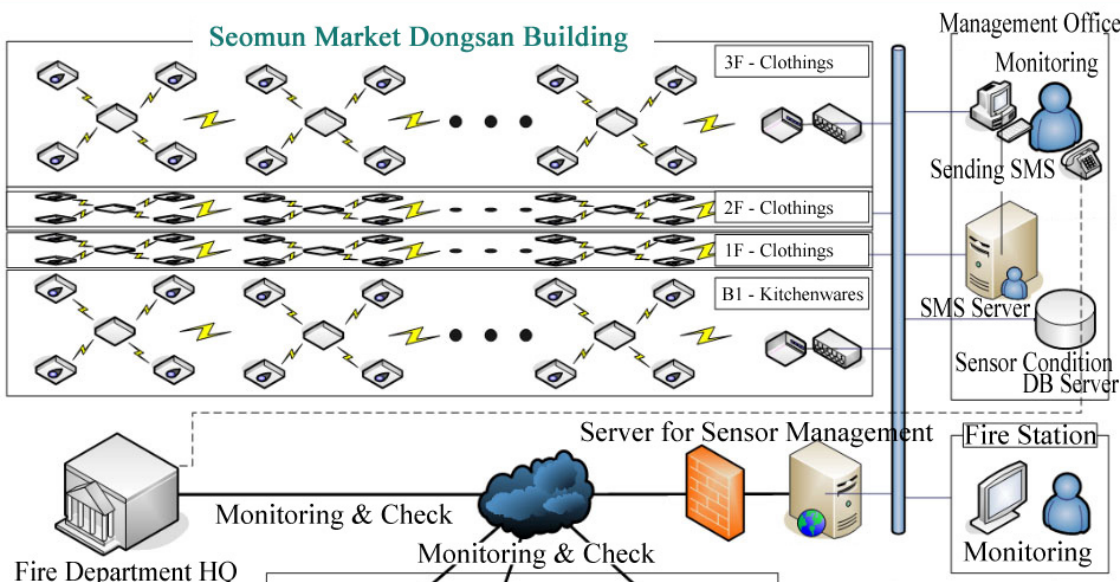

Fire Department HQ

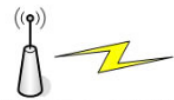

Notification by SMS

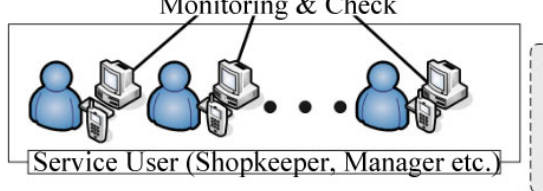

(2) USN Node including Sensor $\checkmark$ USN Node Not including Sensor QUSN Ethernet Gateway

Figure 5: Components of U-FPMS for Fire Protection at Seomun Market. 
USN Management and Statistic Server is linked to the USN Ethernet Gateway Node which collects node and sensor information. It collects the information related to USN Management Services and keeps it to Database Management System (DBMS). It can also monitor the conditions regarding fire protection and it can be operated by remote control. If it detects an indication of fire or a technical obstacle, it instructs the SMS Server to send an emergency message to managers and to alert people near the market place.

Table 2: $\quad$ Primary functions of U-FPMS.

\begin{tabular}{|l|l|}
\hline Detector Terminal & - Line of Sight (LOS): over 100m \\
based on the USN & - Clear of Barriers of Adjacent Terminal \\
& - Able to Check Battery Condition by itself \\
& - Able to Operate over 7 days under emergency \\
& conditions \\
& - Able to Detect Fire, Smoke, Sparks \\
\hline USN Network & - the USN Node is comprised of Sensors \\
& - Wired and Wireless USN Gateway Node \\
& - design for the best place for the installation of \\
& Sensors \\
\hline Monitoring System & - A Display System of Sensor Positioning Conditions \\
& - Fire Alarm System connected with the SMS Server \\
& - Fire Warning System by Accumulated Data \\
\hline Linked with & - Accepting the Fire Report connected with Guarding \\
Fire Department & against Fire \\
& - Telecommunicating Spot Information and Monitoring \\
& Display \\
& - Connected with a Mobilization Order System \\
\hline
\end{tabular}

\subsection{Advantages and potential of the U-FPMS}

The U-FPMS was designed after considering a fire. Primary systems such as Gateway, Gateway Master and Sensor Node were duplicated so as to the monitoring of a fire if more than $20 \%$ of the system is destroyed by fire or if another primary sensor node is destroyed. In order to detect a fire as quickly as possible, the U-FPMS has many combined sensors and each sensor has an identification number which can be used to determine the location of a fire. We are trying to make the U-FPMS affordable and easily accessible with the hope that it can be applied to various environments. The system needs to be able to detect a fire immediately so that the response of the fireplug can be quick and effective. When fire fighters extinguish the fire, they will be able to track how the fire progressed from the information of the USN and RFID tags. Moreover, it should be able to determine the damages and casualties as soon as possible, by attaching the USN node or RFID to the fire fighters or lifesavers. 


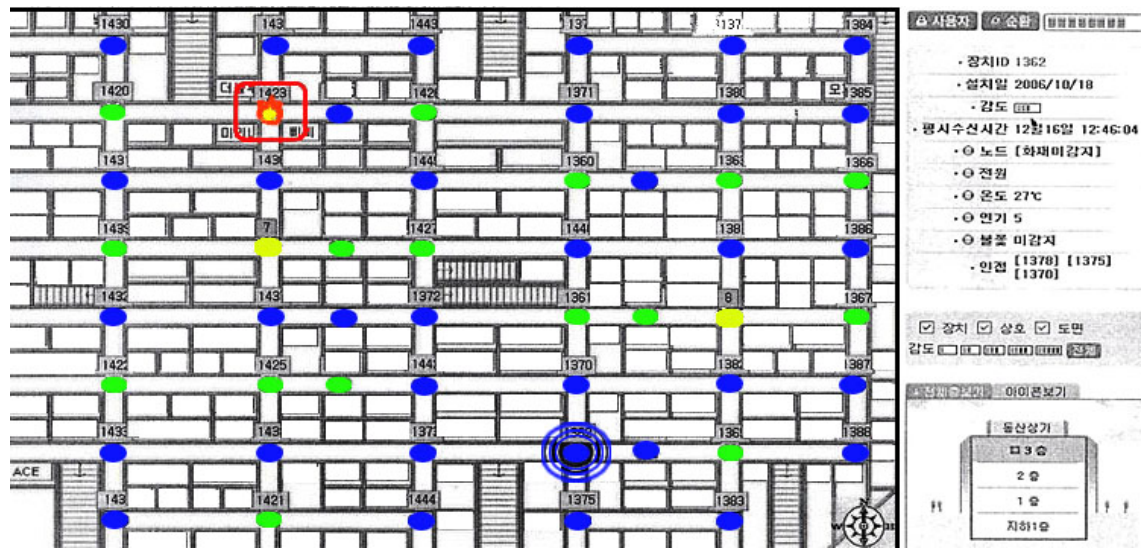

Figure 6: Fire monitoring by U-FPMS: blue point (USN node, including sensor), green point (USN node, not including sensor), yellow point (USN Ethernet Gateway).

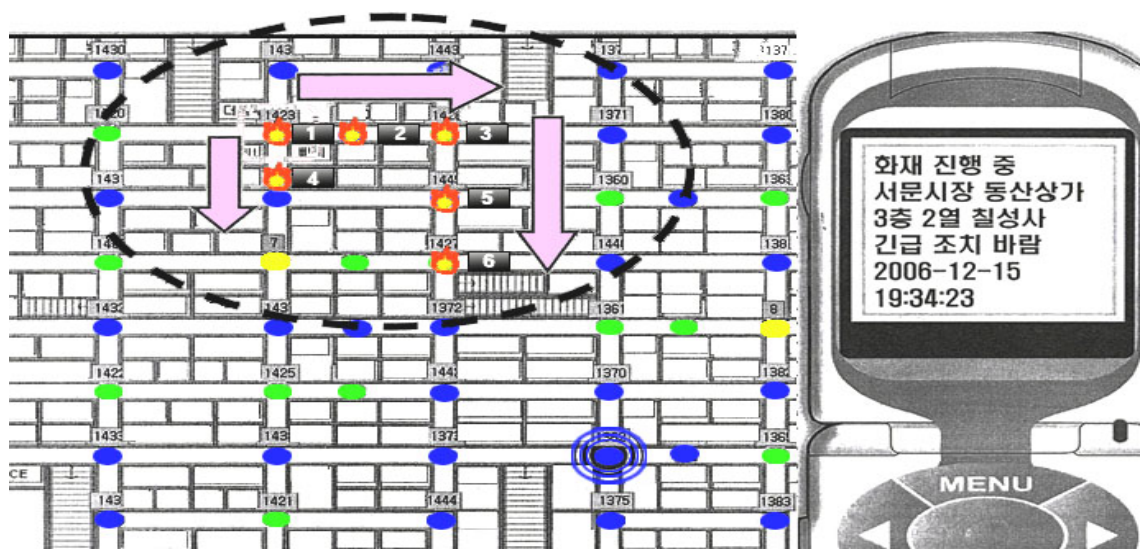

Figure 7: $\quad$ The detection of fire and sending emergency SMS.

\section{Conclusion}

Korean Traditional market places are always under the threat of fire. As a result, fire protection systems are of the utmost importance. The U-FPMS is the first generation of fire monitoring system that uses ubiquitous computing. It can detect smoke, temperature, sparks as soon as possible, monitor the conditions for fire protection and it can be operated by remote control. This system is still developed with the hopes that it will make buildings safer and it will reduce the threat of fire. 


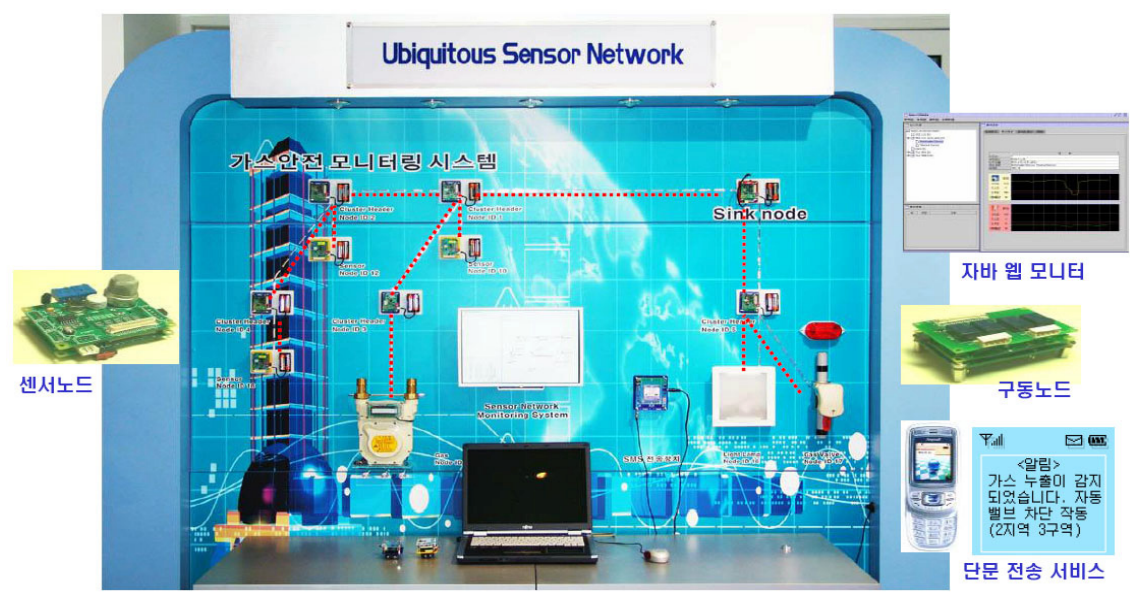

Figure 8: Another USN-based example of a gas safety monitoring system.

\section{Acknowledgements}

This research was supported by the 2nd Storage of Brain Korea 21(2007), the project institution of "Global Expert Training Centre for Disaster Prevention" and the Ministry of Construction \& Transportation, the project institution of "Environmental Improvement about Underground Space and Research on Disaster Prevention Technology" (03san C03-03).

\section{References}

[1] Daegu Fire Department \& Winitech Co., Ltd., The Introduction to UFPMS, the project for supporting e-Government, 2006.

[2] P.S. MA., Electronics and Telecommunications Research Institute, The Introduction to Nano Qplus, 2006.

[3] J.W. Park, G.Y. Jeon. \& W.H. Hong, A Case Study on the Problem of fire safety in Domestic Traditional Market with a Focus of Fire at SeoMoon Market. KIFSE, B-07, pp.263-267, 2006.

[4] J.W. Park, G.Y. Jeon. \& W.H. Hong, A Study on the Way to Improve Fire Safety of Korean Traditional Market. ISAIA, pp.229-232, 2006.

[5] N.S. Lee, An Application for Tracking the Location of Material using RFID and Wireless Network Technology. KICEM, pp.523-528, 2006.

[6] Wikipedia, http://en.wikipedia.org/wiki/Ubiquitous_computing

[7] Nanotechnology Now, http://www.nanotech-now.com/smartdust.htm

[8] National Information Society Agency, http://www.nia.or.kr

[9] Fire Statistical Yearbook issued by National Emergency Management Agency (NEMA), 2005. 